\title{
IMPROVING THE ORGANIZATION OF LABOR FORUM IN THE REPUBLIC OF TATARSTAN: PERSONNEL ASPECTS
}

\author{
Irina A. Akhmetova ${ }^{1}$ \\ Svetlana D. Vdovina ${ }^{2}$ \\ Olga V. Demyanova ${ }^{3}$
}

\begin{abstract}
In the article is substantiated the growing role of regulation of labor as an element of economic stability's control not only of individual companies, but also territorial formations. The research of quantitative characteristics of human resource capacity of specialists in the valuation of work in terms of the extensive parameters (gender, age, level of education, professional experience, etc.) for a group of chemical industry and machine-building complex of the Republic of Tatarstan is presented. The analytical materials on the scientific validity of labor standards and labor intensity accounting for regulations to assess the qualitative characteristics of human resource capacity of specialists in labor norms of the republic are offered. By results of the conducted research the
\end{abstract}

basic directions of increasing human resource capacity of specialists in the valuation of work in the chemical and engineering industries of the republic of Tatarstan are developed.

Keywords: analysis, human resources, work quota setting, quality of labor standards, labor intensity, control system of work quota setting.

\section{Introduction}

The high degree of integration of work quota setting with production and technical, financial and economic spheres of activity of firms involves an increase in the valuation of labor status as an element of management of the economic stability not only of the

\footnotetext{
${ }^{1}$ Kazan Federal University, Institute of Management, Economics and Finance. e-mail: vdovina_kki@mail.ru mailto:vdovina_kki@mail.ru.Tel.89600481985

${ }^{2}$ Kazan Federal University, Institute of Management, Economics and Finance. e-mail: vdovina_kki@mail.ru mailto:vdovina_kki@mail.ru.Tel.89600481985

${ }^{3}$ Kazan Federal University, Institute of Management, Economics and Finance. e-mail: vdovina_kki@mail.ru mailto:vdovina_kki@mail.ru.Tel.89600481985
} 
individual enterprises but also territorial entities.

Maintaining a high ranking economic potential (in absolute value of the gross regional product and industrial output per capita Republic of Tatarstan (RT) among the top ten regions of Russia) implies an appropriate level of human resource capacity of specialists on work quota setting in Tatarstan. The aim of the study was to prepare analytical materials to assess the human resource capacity of specialists on work quota setting for further development of programs to improve the control system rationing of work in the Republic of Tatarstan.

Achieving this goal is provided by the need to resolve a number of problems, in particular on the qualitative composition of experts in work quota setting, indicators of labor standards of scientific validity of different categories of the RFP and performance indicators of law; study accounting practices in the labor intensity of the level of automation and standardization of work quota setting.

\footnotetext{
${ }^{4}$ Nasretdinov. Tendencies of development of the system of infrastructure support of innovative
}

Scientific interest represents the use of the approach in order to take into account the diversity and importance of all the factors that affect the human resource capacity of specialists in work quota setting in the region, and also the interactions of extensive indicators of personnel potential setters in leading industries of the region, with the results of their work (scientific validity of norms of work, the accounting of intensity of work when rationing, work rationing automation level) the basic directions increase of personnel potential of specialists in work quota setting.

\section{Methods}

The assessment of personnel potential of specialists in work quota setting is structured first of all in aspect of extensive indicators. The extensive performance potential of the organization personnel include: personnel structure by sex, age, education level, etc. ${ }^{4}$

Studying of the specified indicators was carried out in 2016 at a number of the enterprises of chemical 
industry of the Republic of Tatarstan

(JSC Nizhnekamskneftekhim, JSC

2. Results

Orgsintez, JSC TASMA Holding

The situation that has developed

Company, JSC KZSK, JSC Nefis) and a

machine-building complex of the

Republic of Tatarstan (JSC Radiopribor,

JSC KVZ, SUE Elektropribor, JSC

Kazan Kompressormash, SUE

Teplokontrol, JSC Kamsky PRZ, JSC

Kamaz-Diesel).

in the enterprises surveyed in terms of the aggregate, reflecting the quantitative characteristics of the human capacity units engaged in the work quota setting, requires careful consideration of the qualitative characteristics of setters (Tab. 1).

Tab.1. The qualitative composition and structure of specialists in work quota setting on the surveyed enterprises in the Republic of Tatarstan

\begin{tabular}{|l|r|r|}
\hline \multicolumn{1}{|c|}{ Name of an indicator } & \multicolumn{2}{|c|}{$\begin{array}{c}\text { Actual value of } \\
\text { indicators }\end{array}$} \\
\cline { 2 - 3 } & Pers. & \multicolumn{2}{|c|}{$\begin{array}{r}\text { Specific } \\
\text { weight, } \%\end{array}$} \\
\hline The number of setters, total: & & 100 \\
Including having: & 286 & 18 \\
Higher economic education & & 30 \\
Higher technical education & 78 & 27 \\
Specialized secondary education & 51 & 25 \\
Secondary technical education & 85 & - \\
Secondary education & 72 & -10 \\
\hline
\end{tabular}




\begin{tabular}{|l|r|r|}
\hline Age groups (years) & 29 & 282 \\
$20-30$ & 32 & 10 \\
$31-40$ & 56 & 11 \\
$41-45$ & 63 & 20 \\
$46-50$ & 61 & 22 \\
$51-55$ & 27 & 22 \\
$56-60$ & 18 & 9 \\
60 and above & & 6 \\
\hline Professional experience (years) & 46 & 16 \\
$0-3$ & 51 & 18 \\
$4-10$ & 65 & 23 \\
$11-15$ & 47 & 16 \\
$16-20$ & 77 & 27 \\
21 and above & & \\
\hline
\end{tabular}

Source: The table is compiled by the results of the questionnaire of surveyed enterprises using the method of statistical groupings

The analysis of data on the number of setters in the context of age groups showed that the proportion of basic reproductive firms surveyed are kept and Figure 1 illustrates that .

The proportion of specialists in work quota setting in the working-age population is more than $90 \%$ of the total number of employees working in enterprises rationing.
For a more detailed analysis of the age structure of the staff look at the well-known social-normal criteria used in the research process of personnel potential of organizations:

- Number of employees in the most productive age (30-50 years) should be around 50\%;

- Number of employees under the age of 30 years and after 50 years in equal shares and should take no less than 50\% of the total amount. 


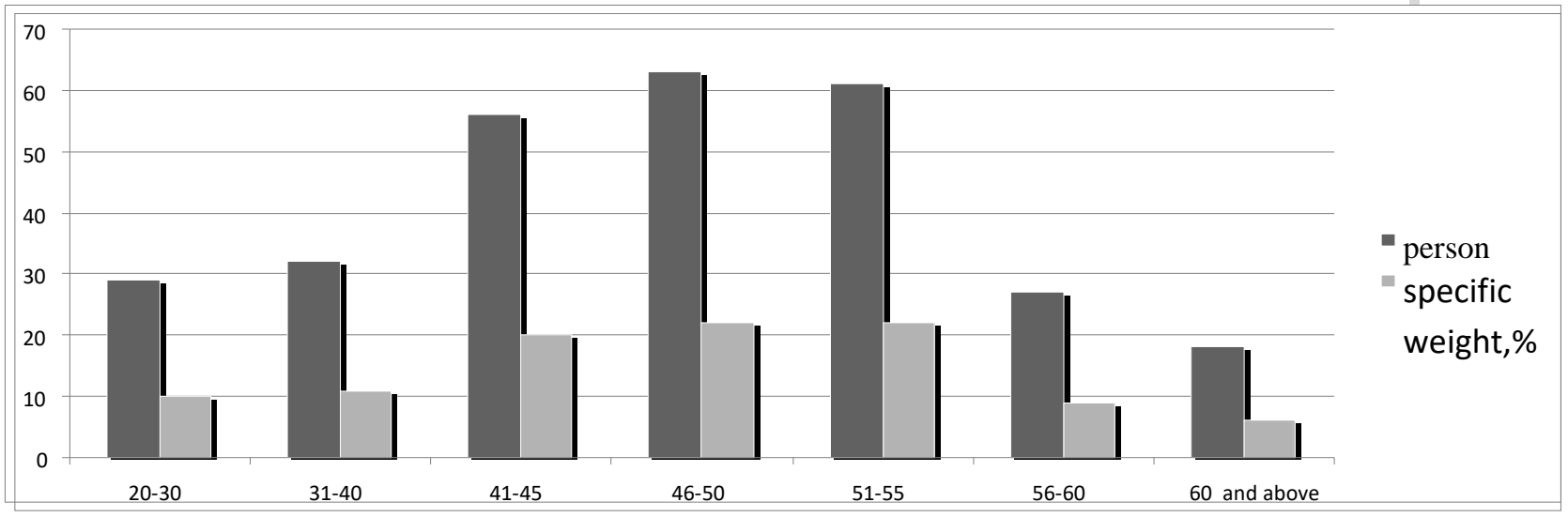

Fig. 1 The age structure of experts on work quota setting at the surveyed enterprises in the Republic of Tatarstan

Source: Chart compiled by the authors is based on the results of the questionnaire surveyed enterprises using the method of statistical groupings.

In the surveyed enterprises the share of productive age setters almost corresponds to the normal social criterion (53 per cent), but the proportion of setters over 50 years is much higher (12 percent), while the share of setters under 30 years is significantly lower (15 percent) of these criteria that it does not allow to evaluate positively the age structure of specialists in work quota setting. The distribution of setters, depending on professional experience (Fig. 2) shows that the largest share in both absolute and relative terms, workers take with experience more than 21 years.

\footnotetext{
${ }^{5}$ Fakhrutdinova, Yagudin. Legislative Provision
}

5 However, the high proportion of inexperienced setters with experience of up to 3 years $(16 \%$, Table 1) at a sufficiently uniform distribution of workers with work experience of 4-20 years indicates a lack of correlation with the distribution of setters age (Fig. 1).

This situation formed as a result of either use of technology leasing specialists in work quota setting having narrow branch specialization within intersectoral labor market either in the course of an open personnel policy, accompanied by a high level of mobility of setters.

As it can be seen from the Table 1 and Figure 3, the implementation of any of these approaches to human resources management at last adversely 
affects personnel potential of specialists

in work quota setting on the criterion of

basic education. ${ }^{6}$

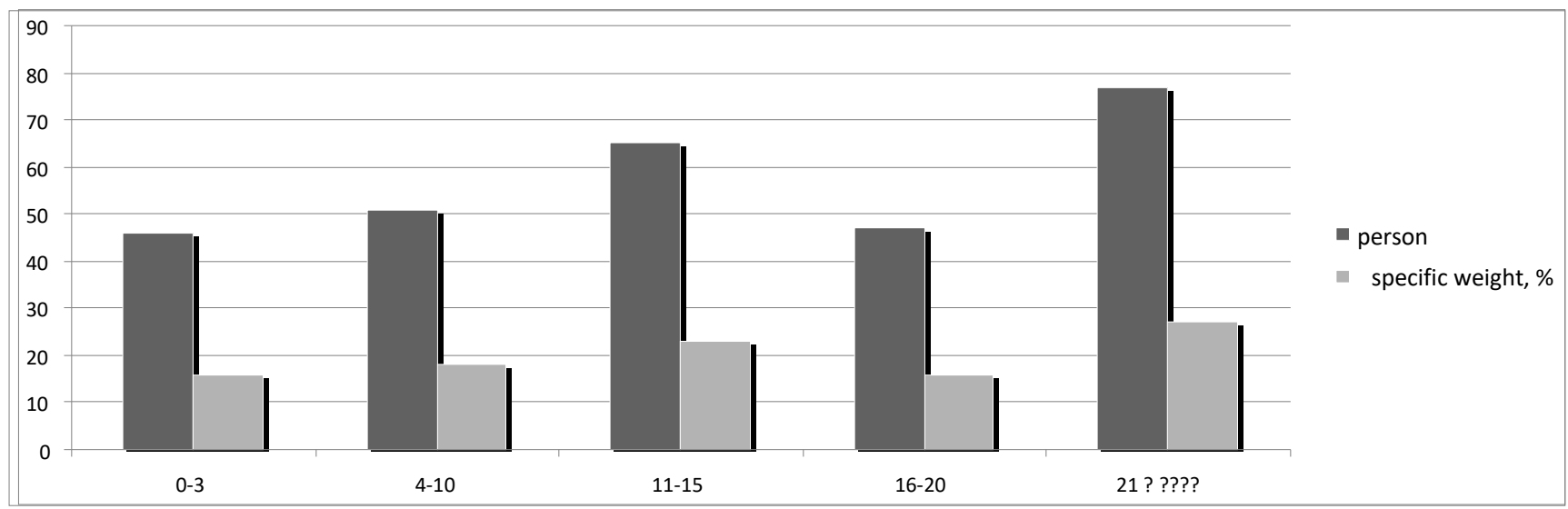

Fig. 2 Composition of specialists in work quota setting in the Republic of Tatarstan on the criterion of length of service

Source: Chart compiled by the authors is based on the results of the questionnaire surveyed enterprises using the method of statistical groupings

In particular, the analysis of the data in the Table 1 indicates that more than half of the professionals working in the field of work quota setting at the enterprises surveyed population, have special secondary education, higher technical education - $18 \%$, higher economic education - $27 \%$ setters.

\footnotetext{
${ }^{6}$ Sharafutdinova, Valeeva. Quality management system as a tool for intensive development of
}

trade organizations J. Mediterranean Journal of Social Sciences 6 (1S3) 2015: 496-498. 


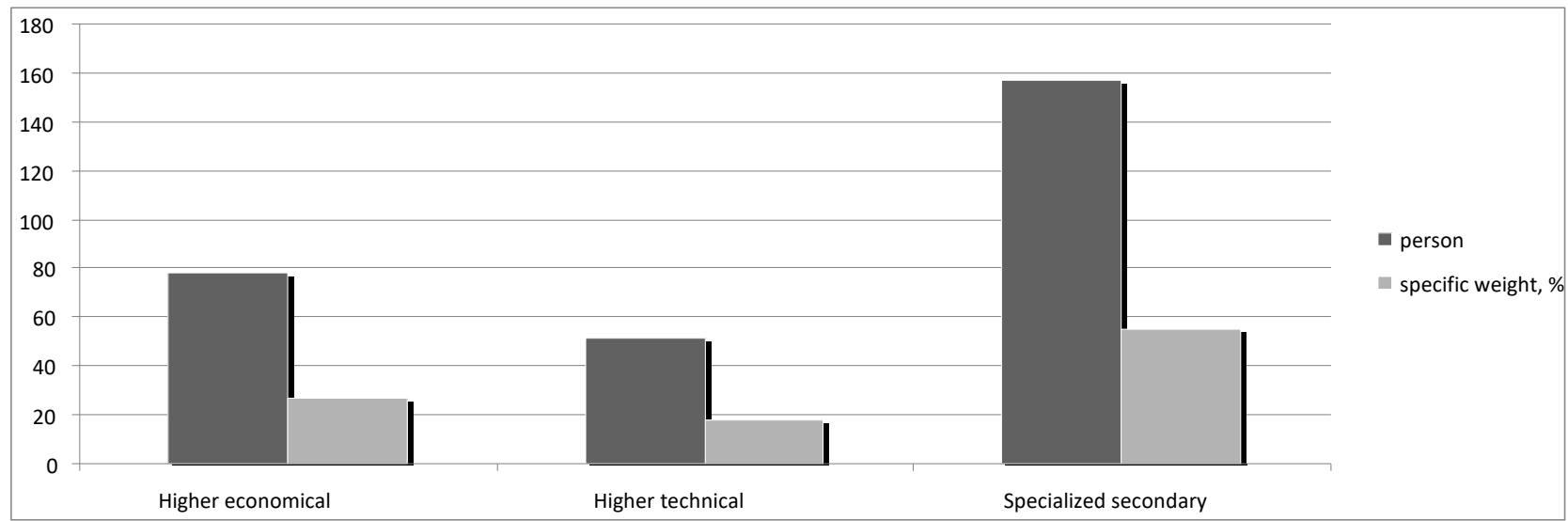

Fig. 3 Composition of specialists in work quota setting in the Republic of Tatarstan on the criterion of basic education

Source: Chart compiled by the authors is based on the results of the questionnaire surveyed enterprises using

\section{Discussions}

It is known that the quality of the method of statistical groupings. the work quota setting is reflected in the

The prevailing forms of rate of utilization of technically based distribution setters for basic education norms (TBN). Information to assess the does not create objective conditions for improving the quality of the quality of existing norms on the development of labor standards. enterprises surveyed are shown in Table 2.

Tab. 2. Specific weight of the technically based and statistical standards used in the surveyed enterprises of the Republic of Tatarstan *

\begin{tabular}{|c|r|l|l|l|}
\hline \multirow{2}{*}{$\begin{array}{c}\text { Name of the } \\
\text { company }\end{array}$} & \multicolumn{3}{|c|}{ Share of the TBN, } & \multicolumn{2}{c|}{$\begin{array}{l}\text { Share of research } \\
\text { and statistical standards, \% }\end{array}$} \\
\cline { 2 - 5 } & Pieceworkers & $\begin{array}{l}\text { Time- } \\
\text { workers }\end{array}$ & Pieceworkers & $\begin{array}{l}\text { Time- } \\
\text { workers }\end{array}$ \\
\hline $\begin{array}{c}\text { The chemical } \\
\text { industry enterprises: }\end{array}$ & 90,5 & 98 & 9,5 & 2
\end{tabular}




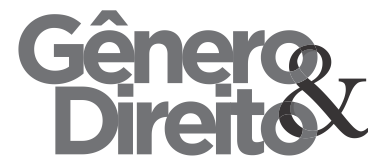

Periódico do Núcleo de Estudos e Pesquisas sobre Gênero e Direito

Centro de Ciências Jurídicas - Universidade Federal da Paraíba V. 8 - No 04 - Ano 2019 - Special Edition ISSN | 2179-7137 | http://periodicos.ufpb.br/ojs2/index.php/ged/index

\begin{tabular}{|c|c|c|c|c|} 
OAO & 88 & 96 & 12 & 286 \\
"Nizhnekamskneftekhim" & 93 & 100 & 7 & - \\
JSC "KZSK" & & & & \\
\hline Engineering & & & & 15 \\
enterprises: & 87 & 85 & 13 & 50 \\
JSC "Kazan & 65 & 50 & 35 & 35 \\
Helicopters" & 75 & 65 & 25 & 13,2 \\
SUE "Electric & 100 & 100 & - & 1,0 \\
appliance" & 71,4 & 74,3 & 1,0 & 19,0 \\
JSC "Kazan- & 82,3 & 72,5 & & \\
Compressormash" & & & & \\
SUE & & & & \\
"Teplokontrol" & & & & \\
OJSC "KAMAZ & & & & \\
diesel" & & & & \\
JSC "Kama RPP" & & & & \\
Total average of & & & & \\
mechanical engineering & & & & \\
\hline
\end{tabular}

* Source: The table is compiled by the results of the questionnaire of surveyed enterprises using the method of statistical groupings. The table 2 includes only those businesses target population which provided relevant data.

The study of the degree of scientific substantiation of labor standards in JSC "Nizhnekamskneftekhim" and OAO
"KZSK" showed that here the proportion TBN on piecework was $90.5 \%$, on a time-paid -98\%. Such parameters can be explained by the interest of leaders and professional training specialists in the work quota setting and the specifics of technological processes (production apparatus). At the enterprises of mechanical engineering index specific weight TBN slightly lower in comparison with the leading enterprises 
of the chemical industry and, consequently, higher than in the chemical industry, the share of research and statistical standards (15-19\%), which is explained, in our view, large volumes work on the work quota setting and the inappropriate amount of labor potential setters. Most commonly they are used in the chemical industry (98$100 \%)$. In the machine-building enterprises the share of the TBN for the pieceworkers of $80.1 \%$ for time-workers - 74.4\%. However, a realistic assessment of the reasonableness of the rules reflects the degree of their implementation. Analysis of indicators of performance standards based on the following assumption: the higher the percentage of compliance with the rules, the lower the quality of their development. ${ }^{7}$ Figure 4 illustrates the results of the distribution of workers according to the degree of compliance with the rules on the surveyed enterprises.

The data in Figure 4 show the high level of performance standards in the production of machine-building enterprises - the average percentage of 160 , with almost $32 \%$ of workers

\footnotetext{
7 Shikhalev, Akhmetova. Using of aggregate indexes in the process of oil export modeling on
}

perform the norm by more than $150 \%$. This situation seems at first sight paradoxical with a high specific gravity of technically based standards. In fact in practice technically based standards include all standards calculated on the basis of timing, that is obtained by analytical - research methods, or based on time limits and modes of operation of the equipment. This leads to the fact that the rules are often set irrespective of how the work is organized, what techniques and methods of work are used as specified modes of operation of the equipment corresponds to the optimal condition.

\section{Summary}

During the research, results are received.

As a result in the number of technically based reach also such standards, which only record the current conditions of work (without their analysis and improvement). Obviously, these rules can not be recognized as high quality and do not differ much from the

an example of the Republic of Tatarstan before the 2009 crisis. Procedia Economics and Finance Vol.4 2013: 55- 63. 
statistics of development. ${ }^{8}$ Approaches used in most enterprises to substantiation standards can not be considered adequate to the situation, which explained by not high personnel potential of specialists in work quota setting.

Maintaining an optimal level of labor intensity in labor standards is also one of the important characteristics of human resource capacity of specialists in work quota setting. ${ }^{9}$ This results from the fact that excessive intensity of work causes inadmissible decrease in working capacity, weakening of attention, care loss that leads to injuries and accidents, increase in a share of the rejected production. Work with low intensity is ineffective, and negatively affects

8 Shikhalev, Vorontsov. The creation of the estimation of the ratio of internal and external resources in the management of extensive and intensive firm development. Conference individual and collective development. Studying of the specified factors on group of the surveyed enterprises allowed to draw a conclusion that for $67 \%$ of the enterprises account of intensity of work is not kept. Only for $33 \%$ of the enterprises intensity of work when developing TBN at a stage of establishment of time for rest is considered. Such enterprises are JSC KZSK, JSC Kazan-Kompressormash, JSC Kamaz-Diesel, JSC Kamsky Press and Frame Plant. This situation allows us to conclude that there are significant opportunities to improve human resource capacity of specialists in work quota setting in the region.
Proceedings political sciences, law, finance, economics and tourism Vol. 4 2014: 701-708.

${ }^{9}$ Shigapova, Valiullin. The Methods of Prediction of Demand on The Labor Market. Procedia Economics and Finance Vol.23 2015: 1476-1479 


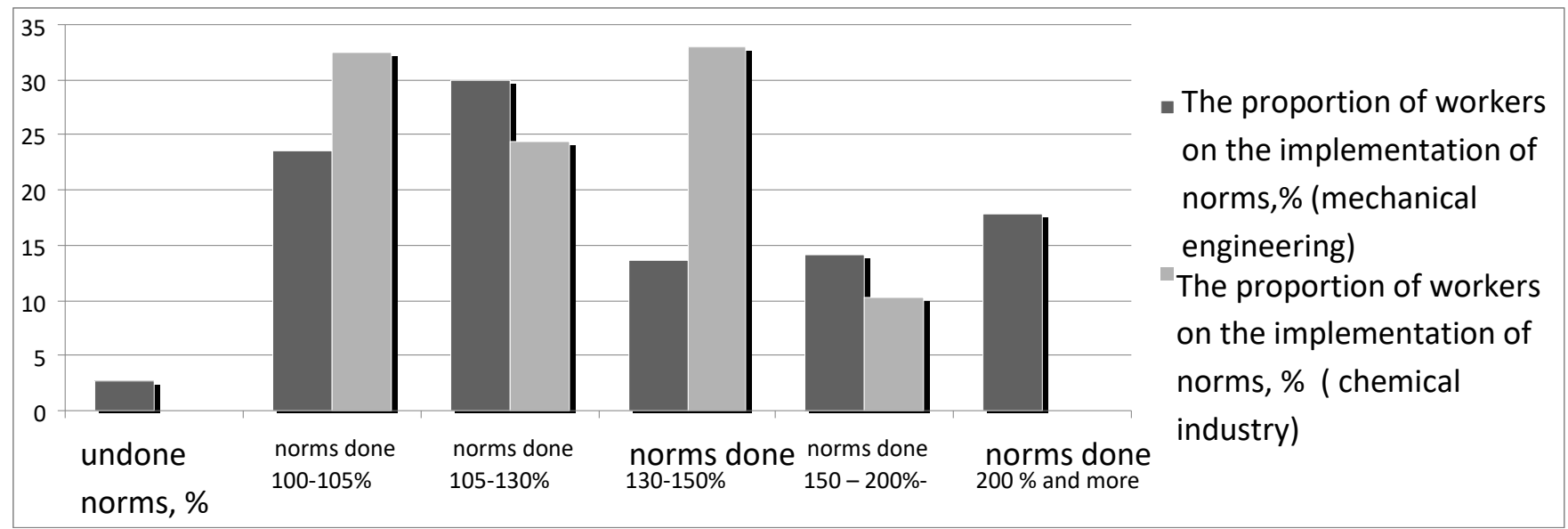

Fig. 4. The distribution of workers by the degree of compliance with the rules in the surveyed enterprises

Source: Chart compiled by the authors is based on the results of the questionnaire surveyed enterprises using the method of statistical groupings

\section{Conclusion}

The analysis of human resource capacity of specialists in work quota setting in the aspect of extensive indicators revealed a rather high level of balanced age structure and length of service in the profession. At the same time, the prevailing distribution of setters in forms of basic education does not create objective conditions for improving the quality of the development of labor standards. Moreover, there are no serious bases to believe that the situation will improve. In curricula of chairs of an economic profile of technical colleges work quota setting as independent discipline is absent. Its studying is limited to separate subjects in rather small amount of hours in the courses "Labour Economics", "Organization, Rationing and Compensation". Questions of work quota setting are almost not studied at the level of secondary spesialized education that affects quality of development of labor norms and a condition of the organization of work quota setting in general.

Serious obstacle on the way of improvement of quality of work quota setting is also insufficient attention paid to professional development of norm 
setters. Only $50 \%$ of the surveyed enterprises carry out purposeful work on professional development of division's employees on work quota setting, and only $33 \%$ from them carried out professional development of norm setters in the scientific research institutes specialized centers of work, the Ministry of Labour and employment of the Russian Federation, institutes of professional development (Moscow).

Nevertheless, despite the low educational level of norm setters, rather good balance of age structure of the personnel in a combination high specific weight skilled workers with an experience more than 21 years. This allows to draw a conclusion on existence of considerable opportunities in this area of labor potential increase of specialists in work quota setting by realization of various forms of their continuous education.

A special place in the work of the selection of continuous education work priorities should take automated methods for calculating the norms and regulations on labor. The use of these technologies can improve labor productivity by $5-7$ times [3], which is especially important for the current situation, characterized by the tendency of reducing the number of setters. Other advantages of the use of calculation automated methods relates to achieve of equal strength standards of time, which provides comfort psychological climate in the workplace, as well as the possibility of calculating the norms of the time in the early stages of production technological preparation, in the absence of technical processes.

Therefore, it's offered to increase personnel potential of norm setters in the Republic of Tatarstan first of all in the following main directions: preparation and professional development of experts in the field of work quota setting; reprofessionalization and continuous education of specialists in work rationing, expansion of the sphere of microelement rationing, automation and computerization of work on standardization of work in a single cycle with computer-aided design of technological processes and organization of work, international cooperation in the field of work quota setting. These directions can be the basis of a regional program to improve the system of management of work quota setting, the implementation of which will ensure the sustained growth of labor productivity, improvement of motivation of personnel, 
increase production efficiency and product competitiveness.

\section{Acknowledgment}

The work is performed according to the

Russian Government Program of Competitive Growth of Kazan Federal University.

\section{Bibliography}

Vdovina S.D. and Runova E.V., 2014. Forecast of the economic effect of the increase in the volume of financing medical equipment supply to the medical institutions of the Republic of Tatarstan. Science Review . Log of, 9 (part 1): 179183.

Demyanova, O.V., 2011 A Multidimensional Model for the Efficiency of a Macroeconomic System.

- Kazan: Kazan University, p. 170.

Horizon 2020. The EU Framework Programme for Research and Innovation.

URL:

http://ec.europa.eu/programmes/horizon $\underline{2020}$

King, R. New Classical Macroeconomics//The

Concise
Encyclopedia of Economics and Liberty. URL:

www.econlib.org/library/Enc/NewClass $\underline{\text { icalMacroeconomics }}$

Marie Curie Actions - Research Fellowship Programme. URL:

http://ec.europa.eu/research/mariecuriea $\underline{\text { ctions }}$

Nasretdinov. Tendencies of development of the system of infrastructure support of innovative entrepreneurship. Resent Trends in Social and Behavior Sciences, Ford Lumban Gaol CRC Press 2015: 209-212.

Sharafutdinova, Valeeva. Quality management system as a tool for intensive development of trade organizations. Mediterranean Journal of Social Sciences 6 (1S3) 2015: 496-498.

Shigapova, Valiullin. The Methods of Prediction of Demand on The Labor Market. Procedia Economics and Finance Vol.23 2015: 1476-1479.

Shikhalev, Vorontsov. The creation of the estimation of the ratio of internal and external resources in the management of extensive and intensive firm 
development. Conference Proceedings

political sciences, law, finance, economics and tourism Vol. 4 2014:

701-708.

Shikhalev, Akhmetova. Using of aggregate indexes in the process of oil export modeling on an example of the Republic of Tatarstan before the 2009 crisis. Procedia Economics and Finance Vol.4 2013: 55- 63 